\title{
Northern scopes
}

\author{
John Morse MD¹, Paul C Adams MD², Editor-in-Chief
}

$\mathrm{D}^{\mathrm{r}}$ John Morse is an Associate Clinical Professor of Medicine at the University of Alberta, Edmonton, Alberta, and the only gastroenterologist in the Northwest Territories (NWT). He currently practices in the city of Yellowknife, NWT.

PA: Can you describe some of the unique challenges of working in the NWT as a gastroenterologist?

JM: The NWT has a small population of 43,000 spread over a huge area of land. In comparison, the population demographics are younger than southern Canada. We also have some unusual diseases, eg, botulism, gastrointestinal (GI) tuberculosis (TB), and a very high incidence of gastric and colorectal cancer.

PA: What attracted you to this type of work?

JM: I was introduced to the NWT during a rotation in my training in Edmonton.

PA: Can you describe your outreach endoscopy program?

JM: Medical travel for patients is highly subsidized in the NWT, so it makes sense to send specialists to remote communities to see patients and perform procedures like endoscopy.

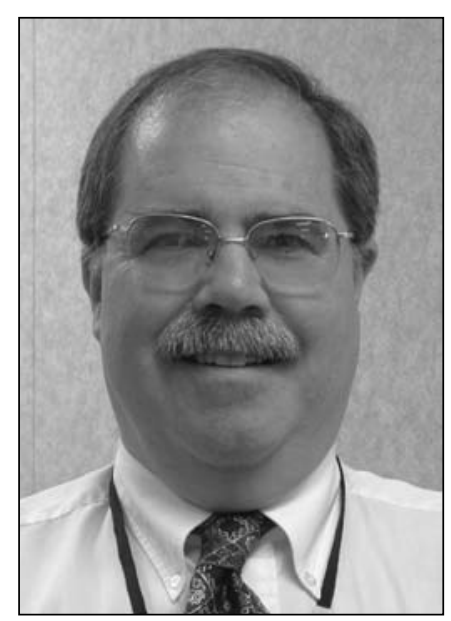

Dr John Morse is an Associate Clinical Professor of Medicine at the University of Alberta, Edmonton, Alberta, and is the only gastroenterologist in the Northwest Territories cultural views on health. We try to work with each patient to maximize the effectiveness of each treatment.

PA: Do you have modern facilities and how often do you transfer patients to Edmonton?

JM: Our hospital in Yellowknife is a secondary care centre with specialist and subspecialist services. Patients needing tertiary care are transferred to Capital Health Authority in Edmonton, where the NWT government has contracted for needed services. I am also the territorial Medical Director, so I need backup from my GI colleagues from time to time. I am also an external partner in the Edmonton GI group, so I have easy access to phone advice on challenging cases. We have three general surgeons in Yellowknife, so they often provide a different point of view on cases. Having medical residents from Edmonton also provides teaching challenges.

PA: What are some of the interesting recreational opportunities that you enjoy in the region?

JM: I like to fish, and I enjoy both of our northern seasons (winter and summer). The community of Yellowknife is culturally and economically robust. It is a great place to raise a family.

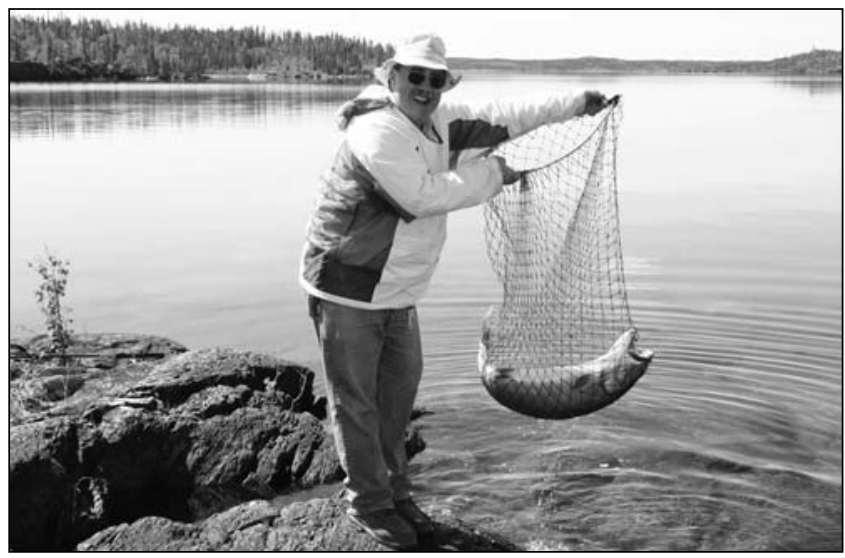

I currently carry out endoscopy clinics located in the towns of Inuvik, Hay River and Fort Smith. In June 2006, I am planning to open a clinic in the new health centre in Cambridge Bay, Nunavut. Elective cases could be performed in travel clinics, while more urgent cases would need to be evacuated to Yellowknife.

PA: What are the common GI problems in the Inuit population?

JM: The older Inuit population, most of whom are carriers, have a high incidence of hepatitis B. Gastric cancer and TB are common problems as well. Over the past year, I have seen a case of TB peritonitis and a cold abscess in the lower left quadrant from Pott's disease.

PA: Is there a traditional medicine approach in the Inuit population? Does it apply to GI diseases?

JM: Each aboriginal group has their unique spiritual and

${ }^{1}$ Department of Internal Medicine, Stanton Medical Centre, Stanton Yellowknife Hospital, Yellowknife, Northwest Territories; ${ }^{2}$ London Health Sciences Centre, London, Ontario

Correspondence and reprints: Dr John Morse, Department of Internal Medicine, Stanton Medical Centre, Stanton Yellowknife Hospital, PO Box 10, Yellowknife, Northwest Territories X1A 2N1. Telephone 867-669-3100, fax 867-920-4271, e-mail john_morse@gov.nt.ca 


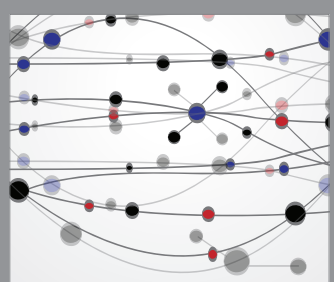

The Scientific World Journal
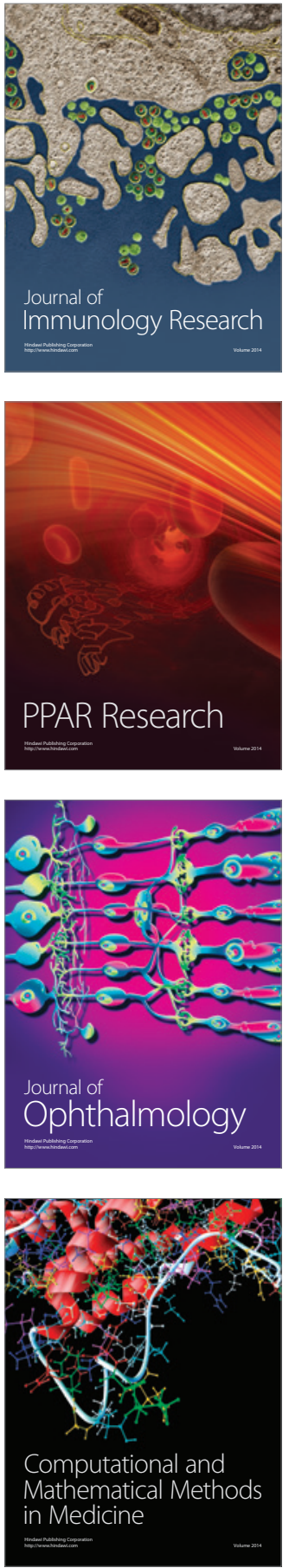

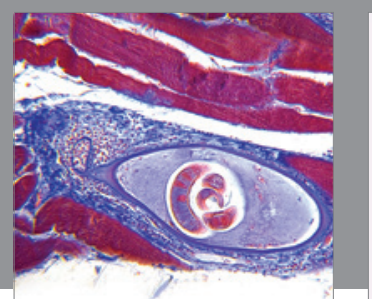

Gastroenterology Research and Practice

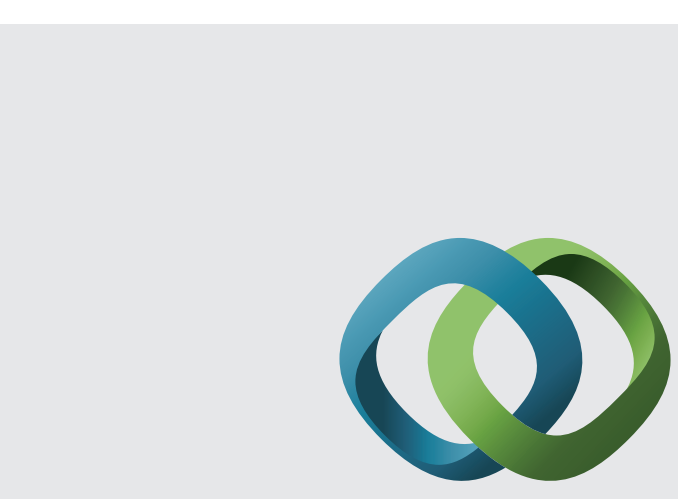

\section{Hindawi}

Submit your manuscripts at

http://www.hindawi.com
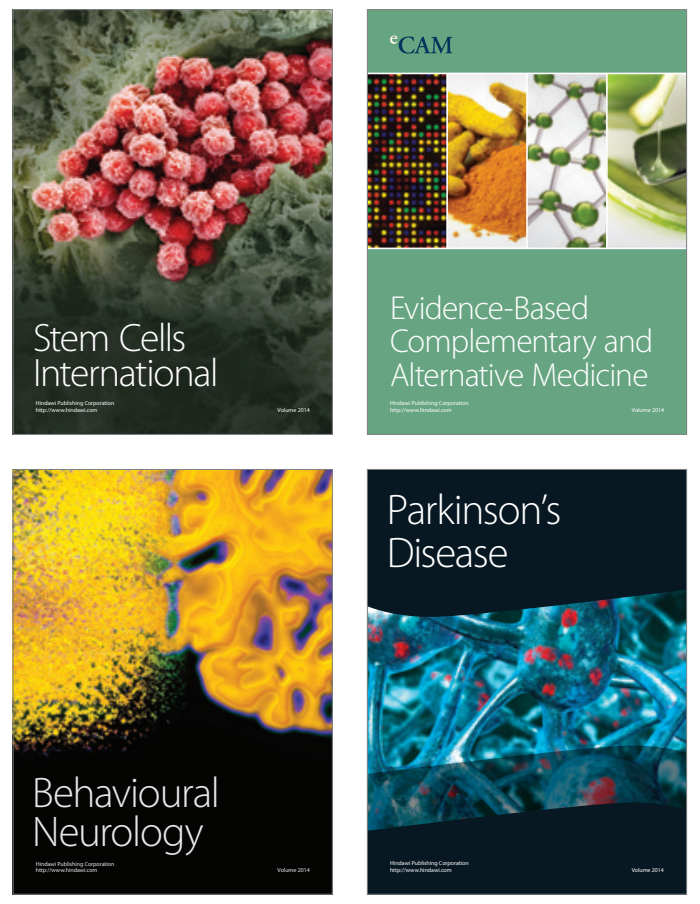
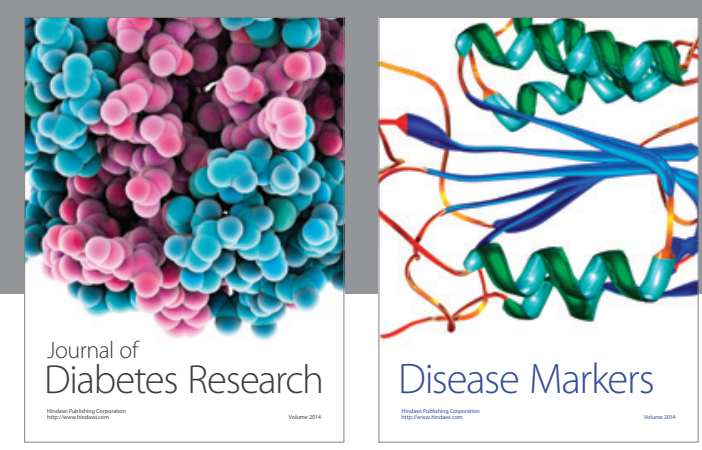

Disease Markers
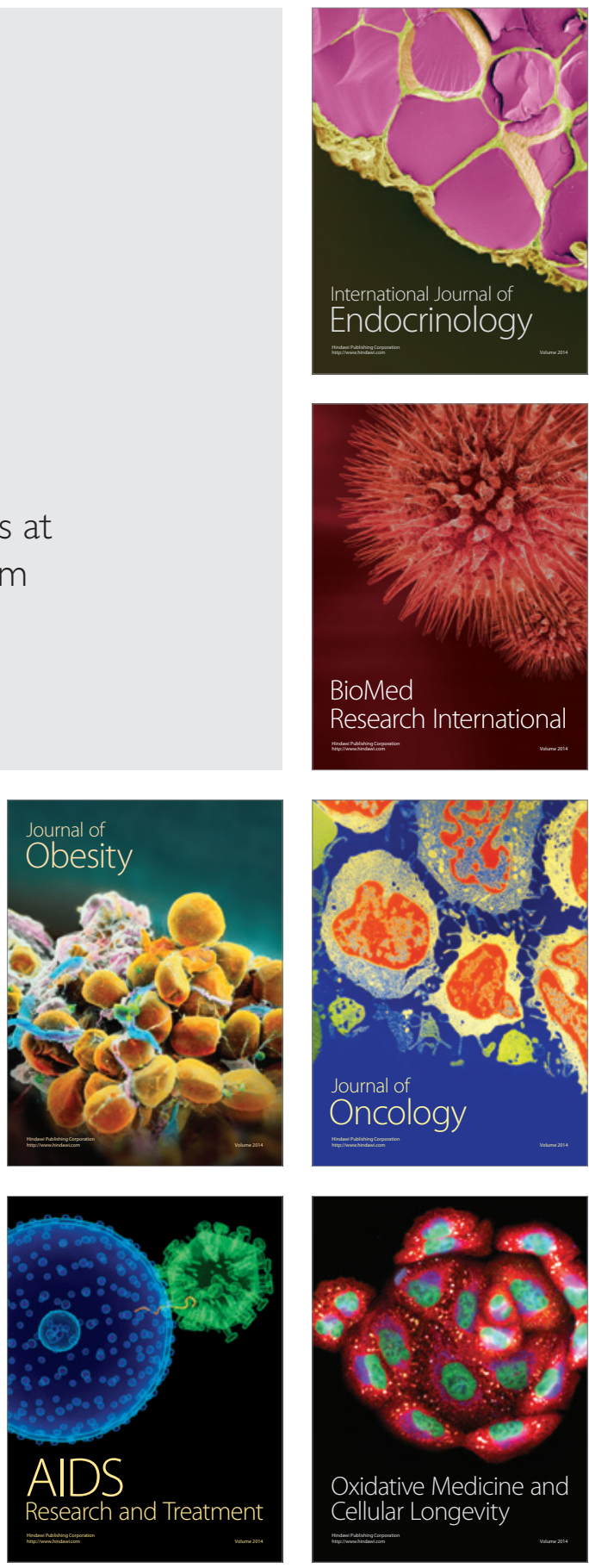